\title{
ABORTO SOCIAL: CONFLITO ENTRE A INTEGRIDADE FÍSICA DA MULHER E OS DIREITOS DO NASCITURO
}

SOCIAL ABORTION: CONFLICT BETWEEN WOMEN'S PHYSICAL INTEGRITY AND BIRTH

RIGHTS

Ana Beatriz Gomes dos SANTOS ${ }^{1}$

ISSUE DOI: $10.21207 / 1983.4225 .582$

\begin{abstract}
RESUMO
O aborto social, no Brasil é uma prática que não pode deixar de ser reconhecida, pois, sua prática é uma constante, em que pese a lei não a amparar. A legislação vigorante, composta da Constituição Federal de 1988, do Código Civil e do Código Penal Brasileiro, tutelam os direitos do nascituro frente aos da mulher enquanto cidadã, no entanto, essa proteção não tem sido suficiente para reduzir ou mesmo para eliminar a prática da realidade social que compõe o cenário brasileiro. Essa situação real faz com que se torne premente pesquisar a respeito da viabilidade da descriminalização da prática. Para tanto, torna-se necessário apresentar o panamorama social vivenciado hoje por mulheres de todo o Brasil, com a criminalização do aborto, através da pesquisa a referenciais teóricos, existentes em obras doutrinárias e em artigos acadêmicos sobre o tema existentes em bancos de dados, como v.g. a Sciello. O sentido do presente trabalho é demonstrar a necessidade de se pensar na possibilidade de descriminalização do aborto, como um meio social de solucionar todos os problemas- ou a maioria deles e consequências que a prática abortiva, de forma clandestina, acarreta às mulheres, que assim se submetem. No entanto, ressalta-se que o presente trabalho, visa ampliar os espaços de discussões sobre a questão, mas sem qualquer pretensão de esgotar os argumentos acerca do mesmo.
\end{abstract}

Palavras-chave: Aborto. Mulher. Direitos Fundamentais. Descriminalização.

\section{ABSTRACT}

Social abortion in Brazil is a practice that cannot be unrecognized, because this practice is a constant, despite the fact that the law does not protect it. The current legislation, made up of the Federal Constitution of 1988, the Civil Code and the Brazilian Penal Code, protect the rights of the unborn child in

\footnotetext{
${ }^{1}$ Aluna do segundo ano de direito da Faculdade de Direito de Franca.
} 
relation to woman. However, this protection has not been sufficient to reduce or even eliminate the practice of the social reality that makes up the Brazilian context. This real situation makes it urgent to investigate the feasibility of decriminalizing the practice. Therefore, it is necessary to present the social panorama experienced today by women from all over Brazil with the criminalization of abortion, through research to theoretical references, existing in doctrinal works and in academic articles on the subject in databases, as Sciello. The purpose of the paper is to demonstrate the need to think about the possibility of decriminalization of abortion as a social means of solving all problems - or most of them and the consequences that clandestine abortion practices entail for women who submit to it. However, it is emphasized that the work aims to broaden the spaces of discussions on the issue, but without any pretension to end the arguments about it.

Keywords: Abortion. Woman. Fundamental rights. Decriminalization.

\section{INTRODUÇÃO}

O Direito à vida faz parte do rol de Direitos Fundamentais e das liberdades públicas inseridas na Constituição Federal, como se transcreve abaixo:

Art. $5^{\circ}$. Todos são iguais perante a lei, sem distinção de qualquer natureza, garantindo-se aos brasileiros e aos estrangeiros residentes no País a inviolabilidade do direito à vida, à liberdade, à igualdade, à segurança e à propriedade $(. . .)^{2}$

Essa realidade constitucional, demonstra a necessidade de levarse em consideração as teorias que procuram determinar o início da vida humana, justamente para que se possa fixar um marco temporal para que a tutela prevista em lei possa viger, dentre outras, as principais são: Concepção, Nidação, Encefálica e do Nascimento.

Sistematicamente, a Teoria da Concepção, defende que a vida humana começa desde a concepção, ou seja, desde a fecundação, sendo, portanto, o feto sujeito de direitos. Tal teoria é adotada pelo atual Código Civil, em seu Art. $2^{\circ}$ : "A personalidade civil da pessoa começa do nascimento com vida; mas a lei põe a salvo, desde a concepção, os direitos do nascituro". 3

Portanto, vale ressaltar que os adeptos desta teoria, em aspectos gerais, abominam o uso do método anticoncepcional de emergência, deno-

\footnotetext{
${ }^{2}$ Constituição Federal de 1988. Disponível em: http://www.planalto.gov.br/ constituicao/constituicao.htm Acesso em: 17 Jul.2017

${ }^{3}$ Código Civil de 2002. Disponível em: http://www.planalto.gov.br/ccivil_03/leis/2002 Acesso em: 17 Jul.2017
} 
minada popularmente como " pílula do dia seguinte", e inclusive, a pesquisa com " células tronco", que foi objeto da ADIN 3.510-Lei de Biossegurança ${ }^{4}$, julgada como constitucional, pelo Supremo Tribunal Federal, que adotou, também, o princípio da proporcionalidade, como se constata:

Assim, julgo improcedente a ação, para declarar a constitucionalidade do art. $5^{\circ}$, seus incisos e parágrafos, da Lei $\mathrm{n}^{\circ} 11.105 / 2005$, desde que seja interpretado no sentido de que a permissão da pesquisa e terapia com células-tronco embrionárias, obtidas de embriões humanos produzidos por fertilização in vitro, deve ser condicionada à prévia autorização e aprovação por Comitê (Órgão) Central de Ética e Pesquisa, vinculado ao Ministério da Saúde.

Na doutrina, a jurista Stella Maris Martínez, em sua obra: “ Teoria da Fecundação ou da Formação do genótipo", traz argumentos muito pertinentes e importantes em relação a teoria da concepção, mencionando que uma vez penetrado o óvulo pelo espermatozoide, surge a vida, distinta, daquela, de seus progenitores - pai e mãe. Ou seja, uma nova vida, titular de um DNA único; inédito e com qualidade de ser humano.

Em contrapartida, a Teoria da Nidação, diz respeito ao fato de que a vida humana só começará, quando o zigoto/ovo houver sido implantado no útero materno, o que ocorre entre quatorze dias, após a concepção, como preleciona Luiz Regis Prado:

\footnotetext{
Destarte, o aborto tem como limite mínimo e necessário para a sua existência a nidação, que ocorre cerca de quatorze dias após a concepção. O termo final é o início do parto, que, conforme examinado, é marcado pelas contrações da dilatação (parto normal) ou com o início dos procedimentos cirúrgicos. ${ }^{5}$
}

Ainda, sobre a questão temporal do início da vida há a Teoria Encefálica, que também é conhecida como Teoria do Sistema Nervoso Central. Referida teoria é assim denominada ante o fato de reconhecer a concepção da vida após a formação do córtex cerebral, que irá ocorrer depois da décima oitava semana de gestação.

Dessa maneira, em se admitir a Teoria Encefálica se estará anuindo a afirmação de que há morte cerebral, por não existir mais atividade do sistema nervoso, autorizando assim, que haja a retirada dos órgãos passíveis de serem objeto de transplante.

\footnotetext{
${ }^{4}$ ADIN 3.510- Lei de Biossegurança. Disponível em: http://www.stf.jus.br/portal/geral Acesso em: 17 Jul.2017

${ }^{5}$ PRADO, Luiz Regis. Curso de direito penal brasileiro: Parte Especial. 2. ed. São Paulo, 2002.
} 
A possibilidade de serem extraídos órgãos humanos quando há morte encefálica, está regulamentada na Lei $\mathrm{n}^{\circ}$ 9.434, de 4 de fevereiro de 1997, in verbis:

\begin{abstract}
Art. $3^{\circ}$ A retirada post mortem de tecidos, órgãos ou partes do corpo humano destinados a transplante ou tratamento deverá ser precedida de diagnóstico de morte encefálica, constatada e registrada por dois médicos não participantes das equipes de remoção e transplante, mediante a utilização de critérios clínicos e tecnológicos definidos por resolução do Conselho Federal de Medicina. ${ }^{6}$
\end{abstract}

Em contrapartida, a Teoria do Nascimento ou Natalista, considera pessoa, sujeito de direitos e obrigações, o ente que nasce com vida, pois, a partir desse momento será considerado como tendo personalidade jurídica, contada da efetivação de seu registro de nascimento.

As teorias apresentadas são as mais usuais para o estabelecimento dos critérios de fundamentação e justificativa para a determinação da dimensão temporal da vida, em que pese a existência de inúmeras outras. Dentre elas, se pode citar a Teoria Condicional, a Embriológica, a Ecológica, no entanto, estas teorias não possuem a mesma relevância das anteriormente citadas, inclusive, pelo de fato de não serem aceitas pela maioria dos doutrinadores.

Mas, há que se ressaltar que mesmos diante do fato de se existirem tais teorias, estas não tiveram o condão de unanimizar a discussão a respeito do início da vida, fazendo com que até o presente momento ainda não se tenha uma definição baseada em critérios epistêmicos que possam lhe garantir a devida credibilidade.

\title{
2 DIREITOS DO NASCITURO X DIREITOS DA MULHER
}

Com fundamento na Teoria Concepcionista, por ter sido esta recepcionada pelo Código Civil, pode-se afirmar ser o início da vida e, portanto, da personalidade jurídica, o momento da concepção, ressaltando Maria Helena Diniz, diz que:

Entendemos que o início legal da personalidade jurídica é o momento da penetração do espermatozóide no óvulo, mesmo fora do corpo da mulher, pois os direitos da personalidade, como o direito

\footnotetext{
${ }^{6}$ Lei de Transplante de Órgãos- Lei $\mathrm{n}^{\circ}$ 9.434. Disponível em: http://www.planalto.gov.br/ccivil_03/leis/L9434.htm Acesso em: 17 Jul.2017
} 
à vida, à integridade física e à saúde, independem do nascimento com vida. Apenas os direitos patrimoniais, como o de receber doação ou herança, dependem do nascimento com vida, conforme a segunda parte do art. 2. ${ }^{\circ}$ do Código Civil. ${ }^{7}$

Diante dessa realidade, não se pode negar haver um conflito consubstanciado nos direitos do nascituro e o de sua mãe, por essa razão, se torna complicado definir com quem estaria o direito.

Direitos Fundamentais, são como o próprio nome diz, fundamentais ao indivíduo, e não podem ser diminuídos ou numa linguagem esdrúxula, colocados em segundo plano; a não ser, por um direito de igual ou maior importância, como a Constituição prevê.

Adiante, é incorreto afirmar que há uma hierarquia entre os Direitos Fundamentais, pois eles findam-se em si mesmos, talvez, pode-se concluir, que há uma hierarquia material e não formal.

Assim, no que tange a solução deste conflito, pode-se resolver pelo princípio da proporcionalidade e o da eficácia das normas constitucionais e, é justamente por estes princípios, que o legislador no Código Penal- norma infraconstitucional- se embasou, quando estabeleceu as hipóteses de aborto facultativo e suas proibições.

Além disso, com a Introdução à Ciência do Direito, Miguel Reale, trouxe uma perspectiva muito satisfatória e interessante sobre a axiologia e a teleologia. A axiologia estuda os valores predominantes em uma sociedade; assim, no ordenamento jurídico normativo, é possível preencher as lacunas que este possui, com os valores sociais. Do mais, a teleologia, estuda a finalidade da norma jurídica; por sua vez, sua aplicabilidade ${ }^{8}$.

Vislumbrando estas duas e imprescindíveis ciências com os direitos fundamentais previstos na Constituição Federal e com as proibições de aborto e a faculdade que a norma denota à prática, torna-se veemente afirmar que os artigos relacionados ao atual crime, na norma penal brasileira, estão ultrapassados, uma vez que não correspondem, concretamente, a preservação e a efetivação dos direitos fundamentais correlacionados com as mudanças sociais.

Também, a finalidade da proibição do aborto não é efetiva com os atuais números de mortes de mulheres, vítimas; sim, vítimas do aborto

\footnotetext{
${ }^{7}$ DINIZ, Maria Helena. Curso de direito civil. 12. ed. São Paulo: Saraiva. v. 1, 2006

8 Direitos e valores no pensamento de Miguel Reale. Disponível em: http://www.revistas.usp.br/rfdusp/article Acesso em: 17/07/2017
} 
clandestino. A meritrocracia não seria um argumento inteligível ${ }^{9}$; conflito de direitos fundamentais, transcedem o senso comum.

Portanto, desde a concepção, há vida- o nascituro possui personalidade jurídica, consequentemente, sua mãe também é sujeito de direitos e obrigações, e para a solução do conflito entre os direitos fundamentais- direito à vida, do feto e dignidade humana, da mulher, o Código Penal valeu-se de hipóteses que facultam o aborto, não sendo, ainda, suficientes para descriminalizar a prática, no todo, e retirar a condição de criminalidade, da mulher; ou seja, algum direito será restringido, no todo ou em parte.

\section{DIREITOS FUNDAMENTAIS: DIGNIDADE HUMANA $X$ DIREITO À VIDA}

Fundamentais:

Rodrigo César Rebello Pinho, assim conceitua Direitos

Direitos fundamentais são os considerados indispensáveis à pessoa humana, necessários para assegurar a todos uma existência digna, livre e igual. Não basta ao Estado reconhecer direitos formalmente; deve buscar concretizá-los, incorporá-los no dia a dia dos cidadãos e de seus agentes. ${ }^{10}$

Quando se trata de Direitos Fundamentais, sabe-se que os mesmos são inalienáveis- intransferíveis e inegociáveis, imprescritíveisnunca deixam de existir, irrenunciáveis- não se pode renunciar, universaisà todos os seres humanos e limitados- limitados a cada pessoa, como sujeito de direito.

Do mais, tratando-se especificamente do Direito à vida- do nascituro e a dignidade humana- da mãe, sabe-se que são direitos de primeira geração, onde visam a liberdade individual e política de cada indivíduo, sendo assim, exigia-se uma abstenção do Estado- não fazer, pois caso o mesmo atuasse, restringiria ainda mais tais direitos.

Adiante, sobre direitos fundamentais correlacionados com o aborto, o Código Penal, assim, delineia:

\footnotetext{
${ }^{9}$ Aborto: A liberdade assusta, mas só exerce quem quiser. Disponível em: http://justificando.cartacapital.com.br/2016/12/05/aborto-liberdade-assusta-mas-so-exerce-quem-quiser Acesso em: 17 Jul.2017

${ }^{10}$ PINHO, Rodrigo César Rebello. Teoria Geral da Constituição e Direitos Fundamentais. 12 ed. São Paulo: Saraiva, v.17, p. 201
} 
Aborto provocado pela gestante ou com seu consentimento:

Art. 124 - Provocar aborto em si mesma ou consentir que outrem lho provoque:

Pena - detenção, de um a três anos.

Aborto provocado por terceiro

Art. 125 - Provocar aborto, sem o consentimento da gestante:

Pena - reclusão, de três a dez anos.

Art. 126 - Provocar aborto com o consentimento da gestante:

Pena - reclusão, de um a quatro anos.

Parágrafo único. Aplica-se a pena do artigo anterior, se a gestante não é maior de quatorze anos, ou é alienada ou débil mental, ou se o consentimento é obtido mediante fraude, grave ameaça ou violência ${ }^{11}$

Disposto isto, incluiu-se nestes artigos, como facultativo, o aborto de anencéfalos- ADPF 54, pois o Supremo Tribunal Federal, assim definiu:

Não se coaduna com o princípio da proporcionalidade proteger apenas um dos seres da relação, privilegiar aquele que, no caso da anencefalia, não tem sequer expectativa de vida extrauterina, aniquilando, em contrapartida, os direitos da mulher, impingindo-lhe sacrifício desarrazoado. A imposição estatal da manutenção de gravidez cujo resultado final será irremediavelmente a morte do feto vai de encontro aos princípios basilares do sistema constitucional, mais precisamente à dignidade da pessoa humana, à liberdade, à autodeterminação, à saúde, ao direito de privacidade, ao reconhecimento pleno dos direitos sexuais e reprodutivos de milhares de mulheres. $\mathrm{O}$ ato de obrigar a mulher a manter a gestação, colocando-a em uma espécie de cárcere privado em seu próprio corpo, desprovida do mínimo essencial de autodeterminação e liberdade, assemelha-se à tortura ou a um sacrifício que não pode ser pedido a qualquer pessoa ou dela exigido. ${ }^{12}$

Observando tal decisão, o STF, determinou inconcebível obrigar uma mulher a gerar e ver nascer um ser humano anencéfalo, uma vez que este, não terá nenhuma expectativa de vida, cominando por fim, sua morte, o que geraria mais transtorno à saúde física e psicológica da mãe, ferindo portanto, sua dignidade humana.

Correlacionado a esta questão, hoje, pesquisas mostram que o aborto clandestino constitui a quinta causa de morte materna no Brasil, ou seja, uma situação que demonstra um grave problema na saúde pública do

11 Código Penal de 1940. Disponível em: http://www.planalto.gov.br/ccivil 03/decretolei/Del2848compilado.htm Acesso em: 18 Jul.2017.

12 ADPF 54. Disponível em: http://www.stf.jus.br/arquivo/cms/noticianoticiastf/anexo/adpf54.pdf Acesso em: 18/07/2017. 
País. Além disso, o Ministério da saúde registra, anualmente, que uma a cada cinco mulheres, já realizou o aborto clandestino. ${ }^{13}$

Diante do exposto, levando-se em consideração que o direito não é anacrônico, e sim, dinâmico; acompanha as mudanças sociais, é urgente e necessário a reformulação dos artigos penais, sobre o tema, assim, como houve com a questão dos fetos anencéfalos- um problema social que exigia uma atuação jurídica. Ou seja, exatamente o que ocorre, atualmente, com as mulheres vítimas e criminalizadas pelo aborto social (será tratado adiante); até porque, são inúmeras as causas que levam mulheres a praticarem o ato e nenhuma, com certeza, concretizá-o com contentamento, uma vez que, é um transtorno.

\section{$4 \quad$ ABORTO SOCIAL NO BRASIL}

Ocorre o aborto social quando uma mulher realiza a prática por não ter nenhuma condição econômica e social para criar o filho, ou seja, quando a pessoa se encontra em situação de miséria, por exemplo. Portanto, este artigo não tratará do aborto sentimental (estupro), do terapêutico (realizado por médico quando há risco de vida da mãe), estes que são permitidos pelo Código Penal; nem dos que são proibidos: aborto eugênico (de fetos deficientes ou que porventura, terão alguma deficiência) e aborto por honra (quando visa proteger a honra da mulher perante a sociedade). ${ }^{14}$

Diante do assunto, o SUS (Sistema Único de Saúde), relatou que em 2013, houve 206.270 internações hospitalares devidas a aborto (espontâneo e provocado); em 2010 foi realizada a Pesquisa Nacional do Aborto (UnB com a ONG ANIS) que concluiu que 1 a cada 2 mulheres que abortam precisam de internação; ou seja, 20-25\% das internações hospitalares são por aborto provocado. ${ }^{15}$

Assim, é possível concluir que há uma déficit grave na saúde pública, uma vez que, estas mulheres, em muitos dos casos, só vão ao hospital

\footnotetext{
${ }^{13}$ Governo afirma à ONU que o aborto clandestino no país é problema de saúde pública. Disponível em: https://oglobo.globo.com/sociedade/governo-afirma-onu-que-aborto-clandestino-no-pais-problema-de-saude-publica Acesso em: 18/07/2017.

${ }^{14}$ MIRABETE, Julio Fabrini. Manual de Direito Penal, São Paulo: Atlas, 1999.

FRANÇA, Genival Veloso. Medicina Legal. Rio de Janeiro:Guanabara Koogan, 2004.

${ }^{15}$ Estatísticas do Aborto. Audiência Pública. Comissão de Direitos Humanos. Senado Federal.05 de maio de 2015. Disponível em: Comissao-Permanente-CDH-20150505EXT021_parte4292_RESULTADO_1430841061822.pdf Acesso em : 18 Jul.2017
} 
quando há complicações decorrentes do aborto clandestino que realizaram, sem o mínimo de assistência médica devida, assim, vão receosas em serem denunciadas à polícia; quando não, morrem sem assistência e no anonimato, como mulheres comuns dentre tantas outras, que também morreram e não tiveram o mínimo de justiça a seu favor, só contra, colocando-as sempre, na condição de criminosas, desnaturadas e para a sociedade, mulheres de má índole. Afinal, a mãe que não assume o filho é vista assim, enquanto isso, os diversos números de abortos paternos- pais que não assumem seus filhos, são "normais", socialmente falando e a pensão paga todo mês, resolve o problema.

Por conseguinte, em uma entrevista com o Dr. Dráuzio Varella, o ginecologista, obstreta e coordenador do Ambulatório de Violência Sexual e de Aborto Legal do Hospital Pérola Byington, em São Paulo, Dr. Jefferson Drezet, relatou números alarmantes de mulheres que fazem aborto no Brasil e dentre os ginecologistas, uma pesquisa brasileira que foi realizada com mais de 10.000 especialistas, menos de $1 \%$ gostariam que a lei fosse modificada para ser mais restritiva ao aborto; ou seja,em profundidade, 60 a $80 \%$ dos ginecologistas brasileiros, acreditam que a lei deveria ser mais aberta e simplificada para a mulher e $16 \%$, gostariam que o aborto, em seu todo, fosse descriminalizado. ${ }^{16}$

Com relação ao abortamento social, mulheres que não têm condições de ter e criar um filho, não deveriam ser tratadas, como a Lei trata do Estupro, por exemplo? Até porque, é uma agressão moral, psicológica, emocional e física, obrigar alguém a prosseguir com a gravidez, simplesmente, porque é mulher e pode gerar filhos, independentemente de sua situação social, visto que, a criança ao nascer, também não terá condições para uma vida digna, o que gera mais pobreza e desigualdade social.

Ou mesmo, diante de tamanho problema, alguém pregar a méritrocracia e culpabilizar a mulher, novamente, não resolve a questão. Assim, a mulher branca e de classe média alta, pode abortar, porque contrata um bom médico para fazer o ato e fica por isso mesmo, afinal é branca e em sua maioria, de classe média à alta. Paradoxalmente, a mulher periférica, sem instrução para planejamento familiar, espancada e estuprada pelo cônjuge- porque ele bebeu e quer sexo, além disso, o mesmo se abstém do uso do preservativo- sem a mínima noção de que está sendo vítima de estupro, engravida e é obrigada pela lei, a ter um filho. Neste caso, por exemplo, não há denúncia por estupro ou qualquer outro crime.

\footnotetext{
${ }^{16}$ Aborto- Jefferson Drezet. Disponível em: https://youtu.be/M0JgvHELtqQ Acesso em: 14 Jul.2017
} 
Do contrário, quando a mulher resolve fazer o aborto clandestino, morre, porque não teve acompanhamento médico; teve culpa, medo, vergonha, dor, e uma vida totalmente desestabilizada, afinal, é uma assassina. Trata-se aqui, de uma tia, de mãe, de irmã, estas que são mulheres comuns, mas que fizeram aborto.

Contextualmente, os países que descriminalizaram o aborto, apresentam uma taxa menor da prática do que os que proíbem o ato. A questão está relacionada ao aumento populacional dos países em desenvolvimento, pois a OMS (Organização Mundial da Sáude), relatou aumento populacional de $88 \%$ nos países pobres- o aborto é um fenômeno significante destes países. ${ }^{17}$

Consequentemente, especialistas analisaram que a alta taxa de aborto nestes lugares, estão relacionadas a falta de acesso a métodos anticoncepcionais, ao planejamento familiar, à saúde e a informação, ou seja, algo extremamente preocupante, tratando-se da era da tecnologia e da informação e provando assim, tamanha desigualdade política, econômica e social, de um país tão vasto e heterogêneo como o Brasil, com o IDH, em geral, mediano e com condições de alimentar toda sua população.

Portanto, quando o assunto é aborto social, correlaciona-se estritamente à misoginia, ao racismo e à sociedade classista ${ }^{18}$; ou seja, à um Brasil Negro e outro, Branco, com IDH discrepante entre os mesmos. Além disso, há uma sociedade paternalista, onde a mulher sempre é culpada pelo fracasso familiar, pela gravidez indesejada, por corresponder seus próprios anseios sexuais, por não conseguir "segurar" seu cônjuge, por ser pobre, negra, desinformada; ou seja, um problema estrutural e que a lei deixa mais enfático, ao ressalvar o aborto como maternal, deixando à margem, o paterno, que é tão relevante quanto ao materno.

Diante disso, quando uma mulher escolhe o não para a maternidade, ela é criticada pela sociedade, se quiser fazer laqueadura, nem na clínica particular consegue realizar o procedimento, com o argumento médico, de que ela pode se arrepender da escolha no futuro; o que é algo machista e hipócrita, uma vez que, o homem, consegue fazer vasectomia

\footnotetext{
${ }^{17}$ Países que liberaram aborto têm taxas mais baixas de casos do que aqueles que o proíbem. Disponível em:

http://saude.estadao.com.br/noticias/geral,paises-que-liberaram-aborto-tem-taxas-mais-baixas-de-casos-que-aqueles-que-o-proibem Acesso em: 19/07/2017.

${ }^{18}$ Criminalização do aborto é misógina, racista e classista. Disponível em: http://justificando.cartacapital.com.br/2017/05/11/criminalizacao-aborto-e-misogina-racista-e-classista Acesso em: 19/07/2017
} 
quando desejar, sem ser julgado, por não querer a paternidade - afinal, é homem.

\section{O CÓDIGO PENAL BRASILEIRO}

Seria, no mínimo, absurdo, em relação a um Código Penal de 1940- diga-se de passagem, de quase 80 anos, afirmar que o mesmo não tenha que ser reformulado em alguns aspectos, como houve com a retirada da expressão "mulher honesta", que só faz exatos 12 anos.

Por conseguinte, recentemente, chegou ao STF, uma ADPF, com o pedido de descriminalização do aborto até a décima segunda semana de gestação. Trata-se, da ADPF 442, apresentada pelo partido do PSOL, tendo por relatora, a ministra Rosa Weber.

Está ação, arguia que a criminalização do aborto, fere a dignidade e a cidadania da mulher. Segue um trecho:

Portanto, na ponderação entre a dignidade como valor intrínseco pertencente ao embrião e a dignidade como autonomia consistente na cidadania das mulheres, deveria prevalecer esta última, não havendo "conflito entre direitos fundamentais, dada a impossibilidade de se imputar direitos fundamentais ao embrião ou feto." (fl. 45 da petição inicial).

Nessa linha, afirma que, "porque somente mulheres engravidam, o direito ao aborto é uma condição de possibilidade para o exercício da cidadania de cada mulher", assim como que "não importam as concepções de bem íntimas a cada mulher; direito ao aborto é condição para a plenitude de um projeto de vida." (fl. 39). Conclui, assim, que impor uma gravidez coercitiva às mulheres ofenderia sua dignidade, na dimensão do respeito à sua autonomia. ${ }^{19}$

Diante disso, o STF não aceitou a ADPF, com argumentos sobre os direitos fundamentais do feto, o que é esdrúxulo, não podendo presumirse, por exemplo, se este sobreviverá até o final da gestação, reprimindo os direitos da mãe, enquanto cidadã; afinal, o direito de abortar, como a citada ação citou, é uma condição para a plenitude do projeto à vida, uma vez que, nenhuma mulher, submete-se a prática com alegria; é sempre um transtorno

\footnotetext{
${ }^{19}$ ADPF 442. Disponível em: file://_442_-_federal_-_codigo_penal_-_aborto_-_legislador_positivo_-
} _direito_comparado_-_ausencia_direito_fundamental_ao_aborto_vf__1_.pdf Acesso em: 19/07/2017 
e há motivos para tal. Assim, é o número de 84 mil mulheres brasileiras que recorreram a interrupção da gravidez, desde o dia 08 de Março de 2017.

Diante disso, se até o STF considera válidas as proibições de aborto, porque foi assim que o Congresso Nacional decidiu, então, o subjugo da mulher ao patriarcado, ainda é aceitável, mesmo depois de 80 anos de Lei Penal. É algo tanto repugnante, especialmente para a mulher pobre e negra, porque a rica e branca, têm condições de fazer o aborto clandestino com segurança de vida e ainda, não sofrer as reprovações de promotores, delegados, juízes e o júri, afinal, não precisa recorrer a justiça para questionar seus direitos- paga por eles.

Segue um trecho da temática, de Luiz Antonio Scavone:

\begin{abstract}
Não podemos desconsiderar a força simbólica dessa interdição penal sobre o imaginário social e subjetivo de quem o pratica, já que há notificações policiais, processos penais, enfim, todo um aparato criminal disponível em torno do aborto, mesmo que ele não resulte em condenação. ${ }^{20}$
\end{abstract}

Por fim, com um código penal retrógrado com relação a este assunto, espera-se então, que a justiça não se esqueça de Jandira Cruz, Elizângela Barbosa e Caroline Carneiro, entre tantas outras mulheres mortas e incriminadas pela Lei, que ao invés de proteger, têm denunciado e exposto as mesmas. Mulheres morrem por abortos inseguros no Brasil.

\title{
6 MULHER E OS ESTERIÓTIPOS SOCIAS
}

Correlacionar mulher com os esterótipos que a mesma detém, é tratar do estigma vinculado à predeterminação social, ao patriarcado, à influência religiosa e ao feminismo.

Infelizmente, em pleno século XXI, o "ser mulher", está correlacionado, ainda, a ideia de mulher branca, heterossexual, cristã, procriadora, submissa, de classe média e passiva. Comprovando isso, a Revista Veja, em Abril do ano passado, lançou uma matéria sobre a primeira dama Marcela Temer, com os seguintes adjetivos persuasivos, abusivos, estagnados e confirmadores de esterióticos patriarcais: Bela, recatada e do lar. Segue uma citação de Donna Haraway e posteriormente, de Rosi Braidotti:

\footnotetext{
${ }^{20}$ SCAVONE, L. Políticas feministas do aborto. Revista Estudos Feministas, [S.1.], v. 16, n. 2, p. 675-680, maio/ago. 2008.
} 
Não existe nada no fato de ser "mulher" que naturalmente una as mulheres. Não existe nem mesmo uma tal situação - "ser" mulher. Trata-se, ela própria, de uma categoria altamente complexa, construída por meio de discursos científicos sexuais e de outras práticas sociais questionáveis. $^{21}$

"Ser mulher" não está relacionado a uma essência biológica prédeterminada, mas a uma identidade construída social e culturalmente a partir das relações sociais e sexuais e pelas práticas e discursos dos saberes disciplinares. ${ }^{22}$

Desde então, Marcela foi vista, com maior ênfase, como modelo de mulher ideal. Diante disso, não se quer criticar o papel de mulher desempenhado por Marcela- ela escolheu isto, porém, não se pode idealizar este à todas, até porque, por uma questão lógica e realista, esta não é a realidade da maioria da mulheres brasileiras, visto que, em sua maioria, trabalham para ajudar no sustento do lar, não são belas segundo o padrão de beleza imposto e muito menos, brancas e de classe média alta.

Adiante, a influência religiosa predetermina a função da mulher, colocando-a como procriadora, assim, ser mulher está estritamento ligado a função maternal e consequentemente, familiar, sendo que, a própria natureza a fez assim, com um útero para gerar filhos. Assim, entra a questão da reprovação do uso de métodos contraceptivos pela Igreja Católica. Ou seja, algo que escrava o sexo feminino e gera uma moralidade impositiva.

Correlacionado a essa questão, existe, também, o fator da medicalização do corpo feminino, este que está vinculado a função procriadora. Assim, este é visto como "santo"; inviolável ou sagrado, o que faz alusão à Maria, mãe de Jesus.

Consequentemente, este assunto, alia mulher à religião, considerando sagrada a gestação e destituindo o ser feminino dos valores morais, sociais e políticos, no sentido de que, uma vez mulher, sempre mãe- ou na maioria da vezes, o que descaracteriza a feminilidade, autonomia e moralidade da mulheres que escolhem não ser mães ou mesmo que não podem gerar filhos.

Diante das questões expostas, entra o movimento social do feminismo. O feminismo visa em um contexto amplo, a autonomia da mulher;

\footnotetext{
${ }^{21}$ HARAWAY, D. Manifesto ciborgue: ciência, tecnologia e feminismo-socialista no final do século XX. In: TADEU, T. (Org.). Antropologia do ciborgue: as vertigens do pós-humano. Belo Horizonte: Autêntica, 2000. p. 33-118.

${ }^{22}$ BRAIDOTTI, R. Sujetos nómades: corporización y diferencia sexual em la teoria feminista contemporânea. Buenos Aires: Paidós, 2000.
} 
sua identidade enquanto mulher, empoderando-a para ser dona de seu corpo, fugindo assim, dos padrões impostos - "Meu corpo, minhas regras"! plana:

Para explicitar melhor tal questão, Luiz Antonio Scavone, ex-

Princípio democrático liberal do direito aplicado ao corpo; direito baseado nas idéias de autonomia e liberdade do liberalismo, expresso na máxima feminista "nosso corpo nos pertence", que se difundiu internacionalmente a partir dos países centrais e marcou as lutas feministas relacionadas à sexualidade, à contracepção e ao aborto. A apropriação do corpo também significava para as mulheres a possibilidade da livre escolha da maternidade. ${ }^{23}$

Portanto, o sujeito mulher é uma ligação de fatores subjetivos e complexos, a cor, etnia, classe social, estilo de vida, sexualidade, fator econômico, religioso, grau de escolaridade e escolha da maternidade. Ser mulher, rompe as barreiras que lhe são impostas, fazendo-a corresponder as suas próprias expectativas, não limitando-as, pelo contrário, maximilizando-as juntamento com o seu potencial, que é forjado e mascarado pelo machismo gritante contra o qual, a mulher luta todos os dias, incessantemente e muitas vezes, involuntariamente.

O feminismo encoraja a mulher a ser ela mesma; ter escolhas, vontades, ambição. Portanto, a sair da marginalização social e impor-se enquanto sujeito de valor jurídico e social- e melhor, sem descaracterizar o papel de outros. Isso sim, é isonomia constitucional e consequentemente, dignidade.

\section{CONSIDERAÇÕES FINAIS}

$\mathrm{O}$ aborto social é um tema polêmico na área religiosa, política e médica, porque contrasta com dogmas, valores e objetivos, afinal, pela concepção, trata-se de uma vida, conflitando então, com os direitos de sua mãe, o que já foi discutido no artigo.

Assim, há uma questão cultural a ser trabalhada gradualmente e uma questão jurídica estagnada, uma vez que as restrições quanto ao aborto no Código Penal, não correspondem em nada com o número alarmante de mulheres que morrem no anonimato, sem o mínimo de assistência médica

\footnotetext{
${ }^{23}$ SCAVONE, L. Políticas feministas do aborto. Revista Estudos Feministas, [S.1.], v. 16, n. 2, p. 675-680, maio/ago. 2008.
} 
e jurídica à seu favor, afinal, morrem como criminosas, pois a lei, não considera seus motivos individuais e degradantes que as levaram à clandestinidade.

Uma a cada cinco mulheres já praticou aborto no Brasil, muitas vezes, por não terem estrutura ou apoio familiar, pelo relacionamento instável com o parceiro, pela falta de planejamento familiar e de recursos para criar com o mínimo de dignidade uma criança e pela questão psicológica e emocional de cada pretensa mãe.

Outra questão, é a omissão do Estado com relação à saúde pública, que não tem o mínimo de estrutura para atender uma mulher sobrevivente após a prátiva abortiva e clandestina, até porque, esta precisa de apoio emocional e psicológico e não julgamentos e denúncias, afinal, fazer um aborto é sempre um transtorno, independentemente do motivo.

Conclui-se então, que esta temática está longe de acabar, afinal, todos sabem que é um problema social e de saúde pública, do qual o menosprezo por parte do Governo e principalmente, por parte da Lei Penal, que em relação a este assunto, está ultrapassada e omissa.

A sociedade enquanto corpo homogêneo também é responsável pelas mortes das mulheres assassinas e anônimas, pois o fardo que estas carregam, são por imposições sociais arcaicas.

Assim, para frisar: nenhuma mulher faz aborto com contentamento. Existe um complexo de sensações de culpa, vergonha, dor e arrependimento que a envolvem, fazendo-a escrava do seu próprio corpo, pelo estigma que este se engloba.

Por fim, aparenta que nascer mulher é carregar um fardo; um carma e a lutar pelo resto da vida; por sua autonomia, dignidade e direito sobre o seu próprio corpo, que na teoria a mesma tem, mas na prática é usurpado todos os dias, desde os padrões de beleza à questão maternal, que sim, limita a mulher em alguma área. Afinal, com a escolha ou não de ser mãe, estará limitada pela família, pelo emprego, pela religião, política, economia ou sociedade. Seja mulher, continue a luta.

\section{REFERÊNCIAS BIBLIOGRÁFICAS}

Aborto- Jefferson Drezet. Disponível em: https://youtu.be/M0JgvHELtqQ. Acesso em: 14 Jul.2017 
Aborto: A liberdade assusta, mas só exerce quem quiser. Disponível em: http://justificando.cartacapital.com.br/2016/12/05/aborto-liberdade-assusta-mas-so-exerce-quem-quiser. Acesso em: 17 Jul.2017

ADESSE, L. Aborto e estigma: uma análise da produção científica sobre a temática. Disponível em: http://www.scielo.br/scielo.php?script=sci_arttext\&pid=S141381232016001203819\&lang=pt. Acesso em: 04 Set.2017

ADIN 3.510- Lei de Biossegurança. Disponível em: http://www.stf.jus.br/portal/geral. Acesso em: 17 Jul.2017

ADPF 54. Disponível em: http://www.stf.jus.br/arquivo/cms/noticianoticiastf/anexo/adpf54.pdf. Acesso em: 18 Jul.2017

BRAIDOTTI, R. Sujetos nómades: corporización y diferencia sexual em la teoria feminista contemporânea. Buenos Aires: Paidós, 2000.

Código Civil de 2002. Disponível em: http://www.planalto.gov.br/ccivil_03/leis/2002 . Acesso em: 17Jul.2017

Código Penal de 1940. Disponível em: http://www.planalto.gov.br/ccivil_03/decretolei/Del2848compilado.htm. Acesso em: 18 Jul.2017

Constituição Federal de 1988. Disponível em: http://www.planalto.gov.br/ constituicao/constituicao.htm. Acesso em: 17 Jul.2017

COSTA,T. Naturalização e medicalização do corpo feminino: o controle social por meio da reprodução. Disponível em: http://www.scielo.br/scielo.php?script=sci_arttext\&pid=S1414-32832006000200007. Acesso em: 04 Set.2017

Criminalização do aborto é misógina, racista e classista. Disponível em: http://justificando.cartacapital.com.br/2017/05/11/criminalizacao-aborto-e-misogina-racista-e-classista. Acesso em: 19 Jul.2017

DIAS, M. Aborto: uma questão social. Disponível em: https://mariaberenicedias.jusbrasil.com.br/artigos/121936049/aborto-uma-questao-social. Acesso em: 04 Set.2017

DINIZ, Maria Helena. Curso de direito civil. 12. ed. São Paulo: Saraiva. v. 1, 2006

Direitos e valores no pensamento de Miguel Reale. Disponível em: http://www.revistas.usp.br/rfdusp/article. Acesso em: 17 Jul.2017

Estatísticas do Aborto. Audiência Pública. Comissão de Direitos Humanos. Senado Federal.05 de maio de 2015. Disponível em: Comissao-Permanente-CDH-

20150505EXT021_parte4292_RESULTADO_1430841061822.pdf. Acesso em : 18 Jul.2017

FERRAZA, D. Medicalização do corpo da mulher e criminalização do aborto no Brasil.Disponível em: http://www.scielo.br/scielo.php?script=sci_arttext\&pid=S198402922016000100017\&lang=pt Acesso em: 04 Set.2017

file://_442_-_federal_-_codigo_penal_-_aborto_-_legislador_positivo_-_direito_comparado_-_ausencia_direito_fundamental_ao_aborto_vf_1_.pdf. Acesso em: 19 Jul.2017

FRANÇA, Genival Veloso. Medicina Legal. Rio de Janeiro:Guanabara Koogan, 2004 
Governo afirma à ONU que o aborto clandestino no país é problema de saúde pública. Disponível em: https://oglobo.globo.com/sociedade/governo-afirma-onu-que-aborto-clandestino-no-pais-problema-de-saude-publica Acesso em: 18 Jul.2017

HARAWAY, D. Manifesto ciborgue: ciência, tecnologia e feminismo-socialista no final do século XX. In: TADEU, T. (Org.). Antropologia do ciborgue: as vertigens do pós-humano. Belo Horizonte: Autêntica, 2000. p. 33-118.

http://www.politize.com.br/aborto-entenda-essa-questao. Acesso em: 04 Set.2017

Lei de Transplante de Órgãos- Lei $\mathrm{n}^{\circ}$ 9.434. Disponível em: http://www.planalto.gov.br/ccivil_03/leis/L9434.htm. Acesso em: 17 Jul.2017

MACHADO, L. Feminismos brasileiros nas relações com o Estado. Contextos e incertezas. Disponível em: http://www.scielo.br/scielo.php?script=sci_arttext\&pid=S010483332016000200301\&lang=pt Acesso em: 04 Set.2017

MAIA, M. Direito de decidir- Múltiplos olhares sobre o aborto.Disponível em: https://books.google.com.br/books?id=DPMmDwAAQBAJ\&pg=PT86\&lpg=PT86\&dq=aborto+social\&source=bl\&ots=qf0TYhkRu2\&sig=112-jVpIUKwqytJhYbb1ckMuH8c\&hl=ptBR\&sa=X\&ved=0ahUKEwiH9a_8uYbWAhXGxpAKHW_gCCI4ChDoAQhOMAY\#v=onepage\&q=aborto\%20social\&f=false Acesso em: 04 Set.2017

MIRABETE, Julio Fabrini. Manual de Direito Penal, São Paulo: Atlas

Países que liberaram aborto têm taxas mais baixas de casos do que aqueles que o proíbem. Disponível em: http://saude.estadao.com.br/noticias/geral,paises-que-liberaram-abortotem-taxas-mais-baixas-de-casos-que-aqueles-que-o-proibem. Acesso em: 19 Jul.2017

PINHO, Rodrigo César Rebello. Teoria Geral da Constituição e Direitos Fundamentais. 12 ed. São Paulo: Saraiva, v.17, pg 201

PORTO,R. Aborto: uma visão humanística. Disponível em: http://www.scielo.br/scielo.php?script=sci_arttext\&pid=S0104-026X2008000200031. Acesso em: 04 Set.2017

PRADO, Luiz Regis. Curso de direito penal brasileiro : parte especial. 2. ed. São Paulo, 2002.

SCAVONE, L. Políticas feministas do aborto. Revista Estudos Feministas, [S.1.], v. 16, n. 2, p. 675-680, maio/ago. 2008.

Serviço Social e Aborto: um debate necessário. Disponível em: http://seminarioservicosocial.paginas.ufsc.br/files/2017/05/Eixo_3_124.pdf Acesso em: 04 Set.2017

VIDAL, A. O aborto em seu aspecto social e sua possível descriminalização. Disponível em: tcc-b206ce483b0c9e2ed0198b8bcf99dd37.pdf. Acesso em: 05 Set.2017

VILLELA, W. Gênero, estigma e saúde: reflexões a partir da prostituição, do aborto e do HIV/aids entre mulheres. Disponível em: http://www.scielo.br/scielo.php?script=sci_arttext\&pid=S2237-96222015000300531\&lang=pt Acesso em: 04 Set.2017 